\title{
The Effect of Training Program Based on Health Belief Model Developed by the Fear of Self-Care Behavior and Hba1c Levels in Patients with Type 2 Diabetes
}

Morteza Porgholmi

MSc. Candidate in Health Education and Health Promotion, Dept. of Health Education and Health Promotion, School of Health, Guilan University of Medical Sciences (GUMS), Rasht, Iran

Rabiollah Farmanbar

* PhD in Health Education and Health Promotion, Dept. of Health Education and Health Promotion, Social Determinants of Health Research Center, Health and Environment Research Center, School of Health, GUMS, Rasht, Iran (Corresponding Author)farmanbar@gums.ac.ir

\section{Parisa Kasmaei}

$\mathrm{PhD}$ in Health Education and Health Promotion, Dept. of Health Education and Health Promotion, Health and Environment Research Center, School of Health, GUMS, Rasht, Iran

Saeed Omidi

Instructor in Epidemiology, School of Health, GUMS, Rasht, Iran

Received: 16 July 2016

Accepted: 30 January 2017

DOI: 10.18869/acadpub.ihepsaj.5.1.65

\section{ABSTRACT}

Background and objective: Diabetes is a serious and a chronic disease. With proper training diabetes can be prevented up to $80 \%$. Therefore, patients with diabetes should be trained in terms of self-care due to the reason that the most important factor of treating diabetes and health care is the patient. This study aimed to determine the effect of training program based on Health Belief Model developed with the fear of self-care behavior and HbA1c levels in patients with type II diabetes in urban-rural health centers in the city of Rasht.

Material and Methods: This is a randomized controlled trial study. The study population were 84 patients with type II diabetes covered by Rasht health centers. They were randomly divided into two groups of intervention $(n=42)$ and control $(n=42)$. Data were gathered through constructs of Health Belief Model developed with the fear of self-care behavior and HbA1c levels before and three months after the test. Control group was not intervened. But the test group were under intervention with 6 sessions of 30-45 minutes, based on pre-tests, using mixed teaching methods such as: speech, discussion, question and answer, role playing with a teaching aid like pamphlets, posters and instructional videos. To analyze the data, descriptive statistics (measures of dispersion and central tendency), chi-square, t-tests and paired t-test was used through SPSS 21.

Results: After intervention, the mean $\mathrm{HbA1c}$ in the intervention group were significantly different. However, the mean $\mathrm{HbA1c}$ in the control group was not significant. The average grade was increased in the experimental group after the intervention, while in the control group this difference was not significant. And the average score of self-care behavior in the experimental group before and three months after the intervention, there was a statistically significant difference $(p=0.001)$. But this difference was not significant in the control group. Conclusion: A detailed training program based on health belief model to increase perceived susceptibility and severity among patients and perceived benefits, and remove perceived barriers with enhancing self-efficacy as well as self-care behaviors in patients and reduction in hemoglobin A1c with type II diabetes is very beneficial.

Keywords: Type 2 diabetes, self-care, Health Belief Model (HBM), HbA1c, Fear model, Rasht.

Paper Type: Research Article.

- Citation (Vancouver): Porgholmi M, Farmanbar R, Kasmaei P, Omidi S. The effect of training program based on health belief model developed by the fear of self-care behavior and hba1c levels in patients with type 2 diabetes. Iran J Health Educ Health Promot Spring 2017; 5(1): 65-72. [Persian]

C Citation (APA): Porgholmi M, Farmanbar R, Kasmaei P, Omidi S. (Spring 2017). The effect of training program based on health belief model developed by the fear of self-care behavior and hba1c levels in patients with type 2 diabetes. Iranian Journal of Health Education \& Health Promotion., 5(1), 65-72. [Persian] 


\section{تأثير برنامه آموزشى بر اساس الكَوى اعتقاد بهداشتى توسعهيافته با التَوى ترس بر رفتار

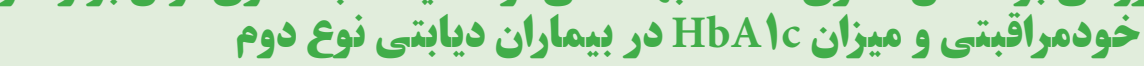

\section{بكيده}

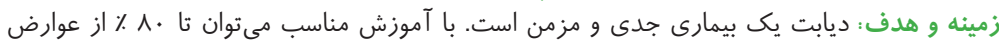

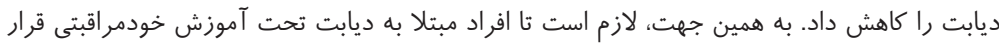

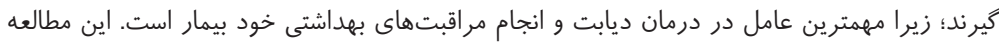

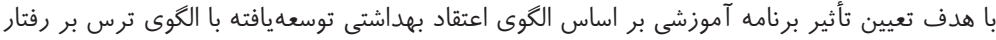

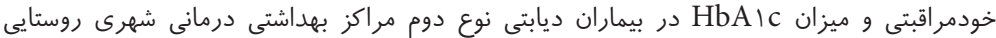
شهرستان رشت انجامشده است.

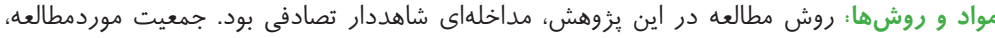

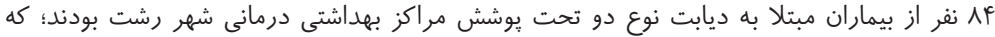

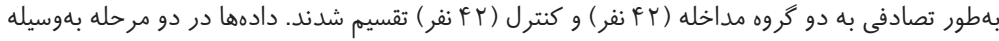

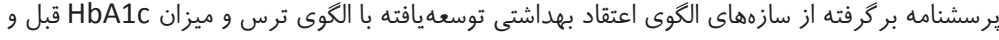

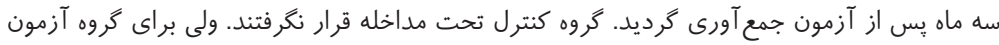

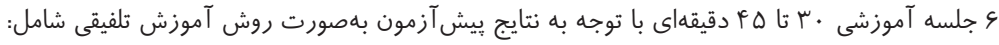

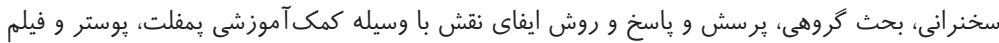

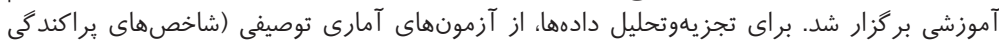

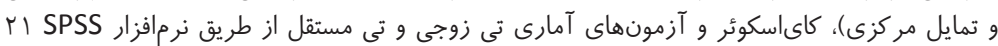

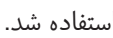

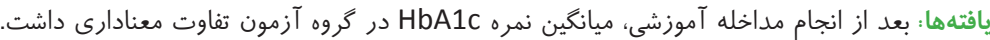

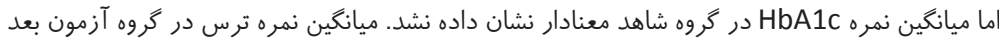

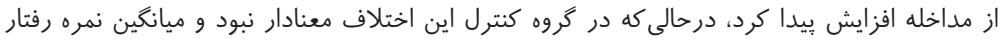

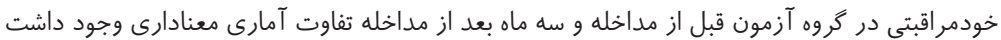

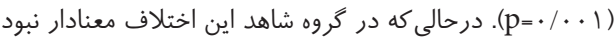

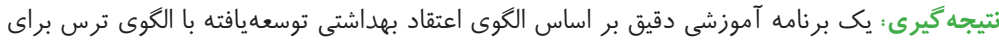

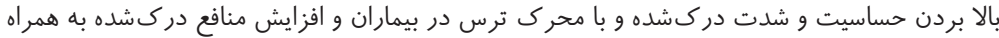

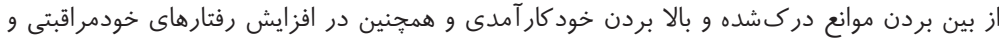

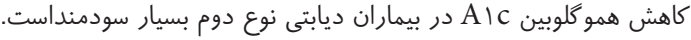

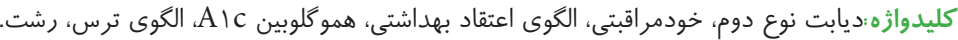

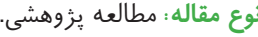

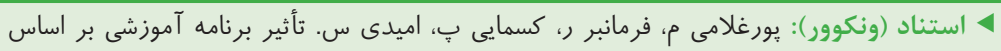

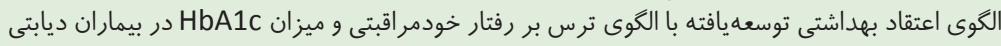

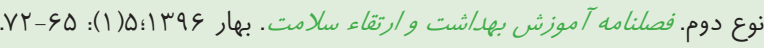

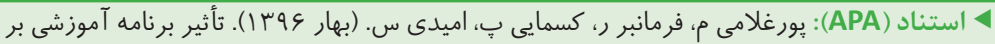

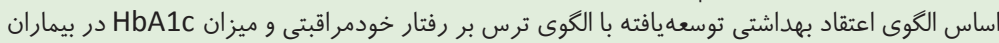

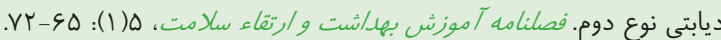

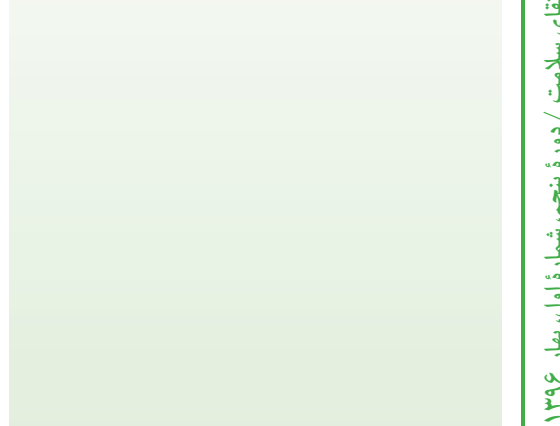

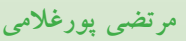

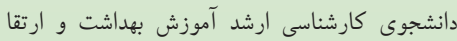

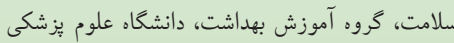
كيلان، رشت، ايران كروه امت بان ربيع اله فرمانبر

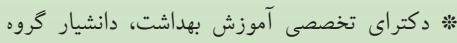

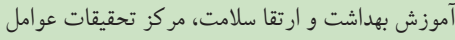

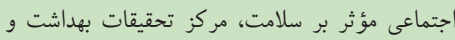

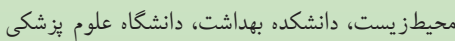

كيلان، رشت، ايران (نويسنده مسئول) farmanbar@gums.ac.ir

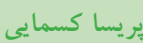

دكتراى تخصصى آموزش بهداشت و ارتقاء سلامت،

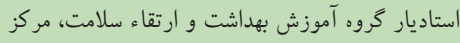
تحقيقات بهداشت و محيطزيست، دانشكده بهداشت، دانشكاء علوم يزشكى گيلان، رشت، ايران

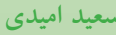
مربى ايبدميولوزى، دانشكده بهداشت، دانشكاه علوم يز شيكى كيلان رشت ايران

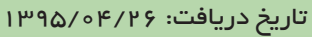

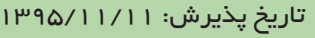


تهديد دركشده را، بهصورت مناسبى تشخيص دهد. ابهام در

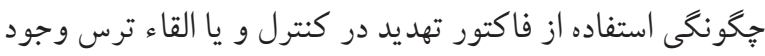
دارد. يك وضعيت نامشخص مابين برانكيختخى ترس و تهديد دركشده ديده مىشود (9). در بيشتر مطالعات تهديد دركشده براى طراحى مداخلات استفاده مىشود. بنابراين، الخوى محرى ترس بيشنهادشده است. به نظر مىرسد ترس مى تواند بهعنوان عامل تغيير رفتار با تقويت ساير سازههاى الخوى اعتقاد بهداشتى مورداستفاده قرار گيرد ( (). لذا با توجه به موارد بيانشده در شيوع روزافزون بيمارى ديابت بهعنوان يك مسئلة بزرگ بهداشتى و اهميت و نقش تعيين كنندهاى كه خودمراقبتى در ارتقاى سلامت و كيفيت زندگى بيمار ان ديابتى دارد، مطالعه حاضر بهمنظور تعيين تأثير برنامه آموزشى بر اساس الگوى اعتقاد بهداشتى توسعهيافته با الكوى ترس بر رفتار خودمراقبتى و ميزان HbA1C در بيماران ديابتى نوع دوم در شهرستان رشت انجام شد.

مو اد و روش ها

محيط يزوهش خانهاى بهداشت تحت يوشش دو مركز بهداشتى درمانى شهرى و روستايى از مجموع Fr مراكز بهداشتى درمانى شهرى روستايى شهرستان رشت بود. نمونهاى يُروهش به روش تخصيص تصادفى انتخابشدند. براى تعيين حجم نمونه با توجه به مطالعات انجامشده در كذشته (V) و با در نظر كرفتن ه / •

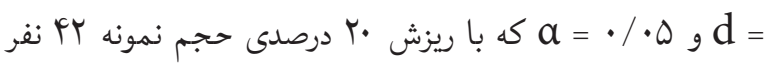
به دست آمد. معيارهاى ورود مشاركت كنندگان در مطالعه داشتن بيمارى ديابت نوع دوم تحت درمان و حداقل •• سال بود. معيار خروج از مطالعه نيز عبارت بودند از: غيبت بيش از يك جلسه در جلسات آموزشى يا مهاجرت در حين مداخله. در اين يزوهش ابزار جمع آورى دادهها شامل اين موارد بود: ابزار شاخص استانداردشده ترس، شاخص استاندارد ترس در قبل از برانخيختخى ترس و پِ از مداخله براى برانگيختكى ترس. اين شاخص دار اي · • إقمت است كه •-. • نشاندهنده بدون ترس و · ا نشاندهنده ترس غيرقابلتحمل است. خود طيف

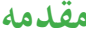

بر اساس آمار سازمان جهانى بهداشت، با افزايش جمعيت، شيوع

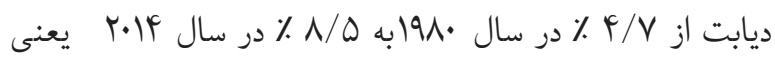
تعدادكل افراد ديابتى دو بوابر شده است اين موضوع افزايش عوامل خطر مرتبط مانند اضافهوزن يا جاقى را نشان مىدهد. تعداد مبتلايان به ديابت در ايران شيوع •الم درصدى (9/9 در مردان و 11/ 1 ز زنان) را نشان مىدهد. قند خون بالاتر از حد مطلوب باعث افزايش خطر بيمارىهاى قلبى و عروقى و درنتيجه افزايش Y/T ميليون مرگومير خواهد شد؛ كه سج ٪ مرگومير قبل از سن • Vالحى رخ مىدهد. در حال حاضر، ديابت نيز ينجمين علت مرگومير در جوامع غربى و جهارمين علت شايع مراجعه به يزشك است (1). ديابت با اختلالهاى مختلف در متابوليسم كُلوكز، يروتئين و جربى همراه است. افزايش مزمن قند خون نيز موجب تخريب، اختلال عمل و نارسايى عضوهاى مختلف به خصوص جشممها، كليه ها، اعصاب و قلب و عروق مىشود (Y). خودمراقبتى در ارتقاى كيفيت زندكى و در كاهش هزينهها مؤثر

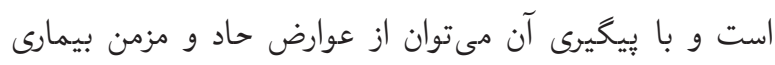

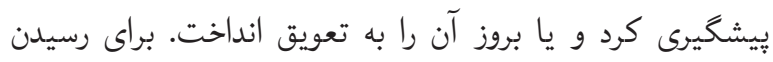
به جنين اهدافى نيازمند مشاركت بيمار در امر خودمراقبتى و آموزش يويا و مستمر است (َا).

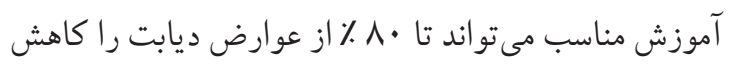

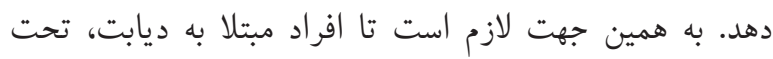

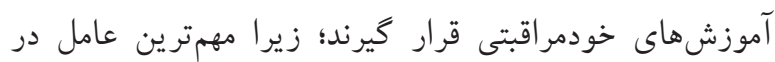

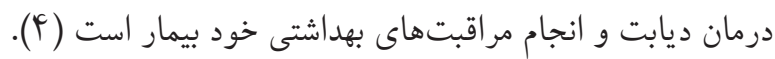

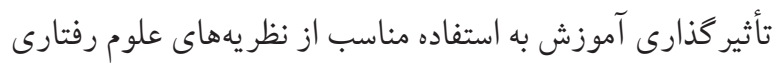

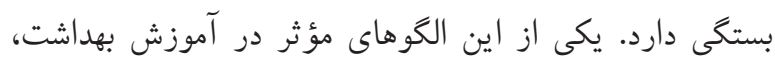

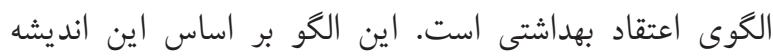

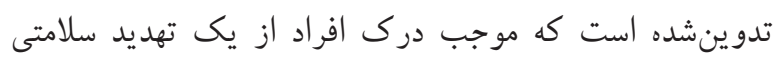

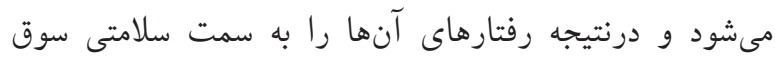

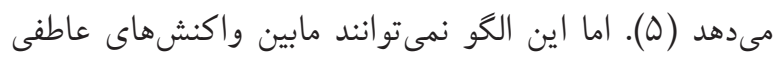
(هيجانى)، مثل برانكيختكى ترس و واكنشهاى شناختى مانند 


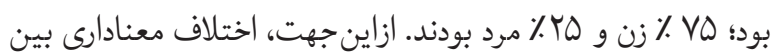
دو گروه وجود نداشت. توزيع دو گروه از نظر سطح تحصيلات، مدت ابتلاو همجنين تأهل شرايط نسبتاً يكسانى بود (جدول لو (1).

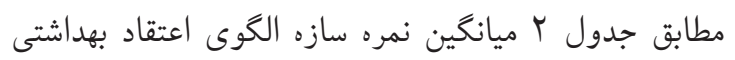
(حساسيت، شدت، ترس، منافع، موانع دركشده و خودكار آمدى)

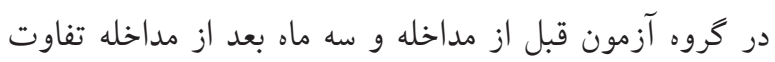
آمارى معنادارى وجود داشت. درصورتى كه در كروه شاهد اين اختلاف معنادار نبود. همجنين قبل از آموزش، آكاهيى بيماران

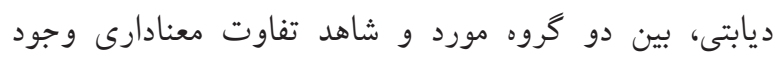

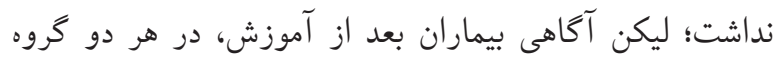

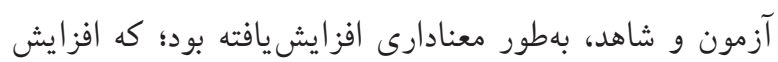

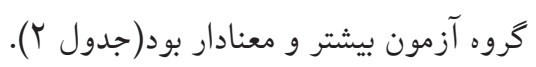
مصرف منظم دارو و كنترل منظم قند خون، در گروه آزمون،

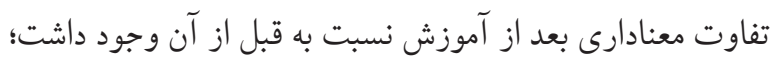
اما در كروه شاهد، قبل و بعد از آموزش، تفاوت معنادارى مشاهده

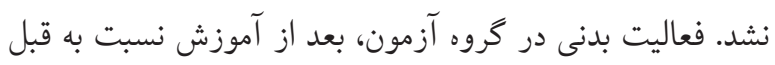

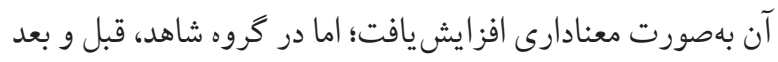

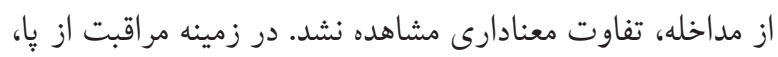

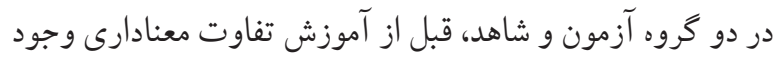

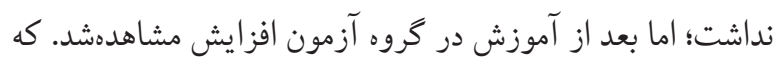

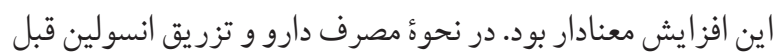

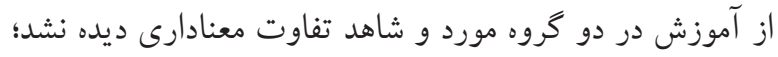

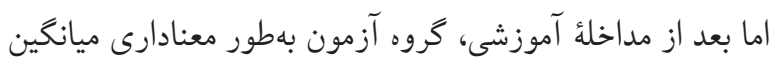

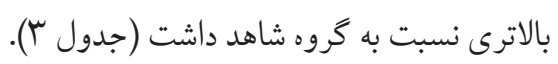
بر اساس جدول F ميزان HbA1C بيماران گروه مداخله قبل

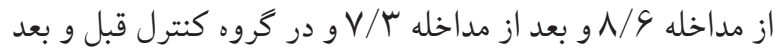

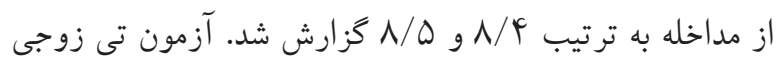

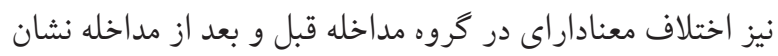

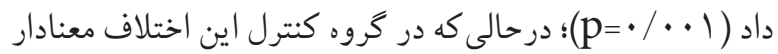

$$
\text { نبود }
$$

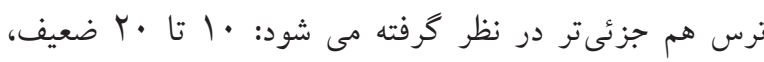

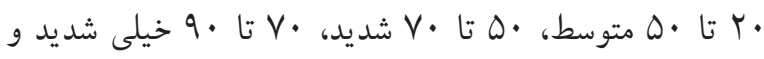

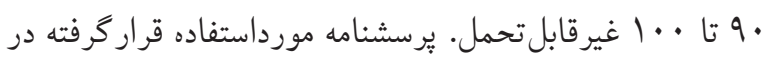

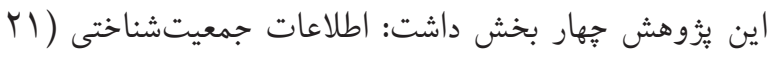

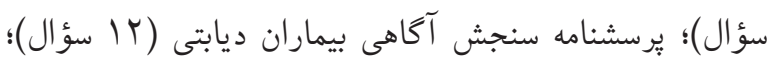

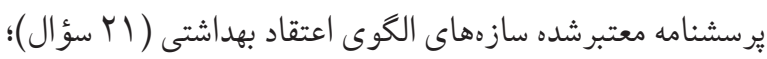
و بيرسشنامه خودمر اقبتى معتبر شده ( إ سؤال). براى روايى برسشنامه از روش روايى محتوايى استفاده شد.

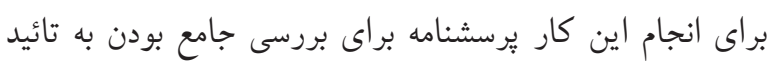

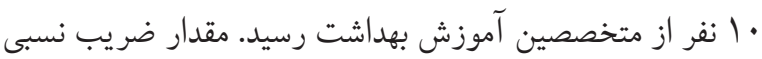

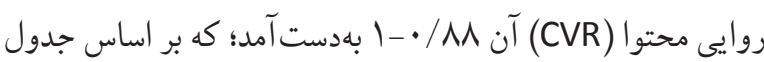

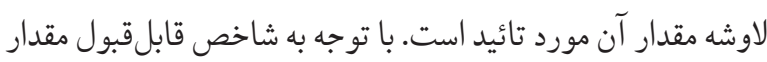

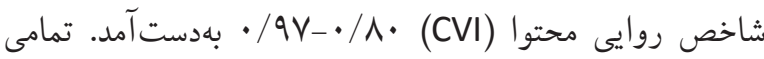

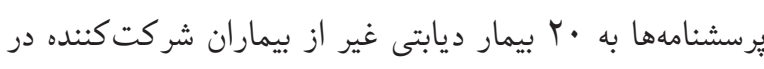

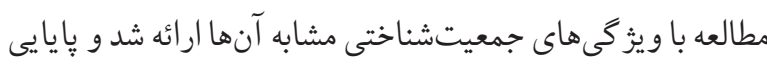

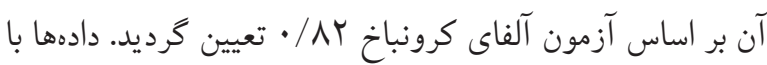

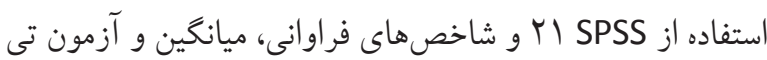
مستقل، تى زوجى و كاى اسكوئر تجزيهو تحليل شدند.

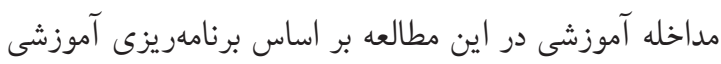

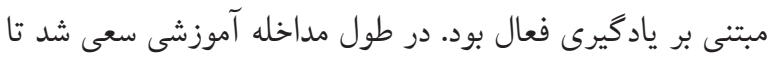

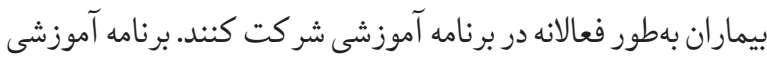

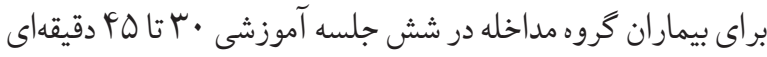
بهصورت سخنرانى، بحث گروهى و روش ايفاى نقش همراه با وسيله

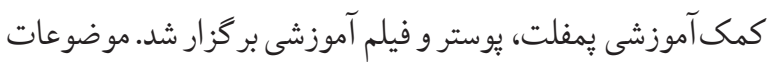

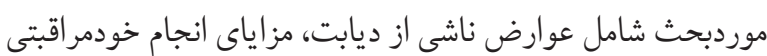
در بيشخيرى از عوارض، اهميت داشتن فعاليت بدنى مناسب، اهميت

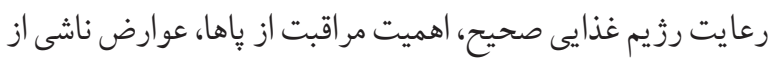
مصرف سيگار در بروز عوارض در بيماران ديابتى بود. يافته ها

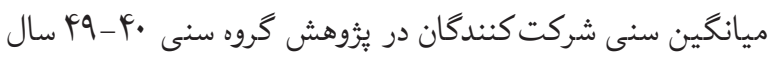


جدول ا. مشخصات جمعيتشناختى افراد شركت كننده در مطالعه در دو گروه مورد و شاهد

\begin{tabular}{|c|c|c|c|c|c|c|}
\hline \multirow{2}{*}{\multicolumn{2}{|c|}{ ويز كىهاى جمعيتشناختى }} & \multicolumn{2}{|c|}{ كروه آزمون } & \multicolumn{2}{|c|}{ كروه شاهد } & \multirow{2}{*}{ p-value } \\
\hline & & \multirow{2}{*}{ تعداد } & \multirow{2}{*}{ درصد } & \multirow{2}{*}{ تعداد } & \multirow{2}{*}{ درصد } & \\
\hline \multirow{3}{*}{ جنسيت } & زن & & & & & \multirow{2}{*}{$\mathrm{p}=1$} \\
\hline & مرد & 1. & rF & 1. & rF & \\
\hline & جمع & fr & $1 \cdots$ & fr & $1 \cdots$ & \multirow{8}{*}{$\mathrm{p}=\cdot / 9 \vee 1$} \\
\hline \multirow{7}{*}{ كروه سنى } & $\mu q-r$. & $\Delta$ & r & $\checkmark$ & ir & \\
\hline & $p q-r$. & rs & 10 & rs & 10 & \\
\hline & $\Delta q-\Delta$. & שr & If & r & ir & \\
\hline & +9 & rs & 11 & rs & 11 & \\
\hline & 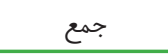 & fr & $1 \cdots$ & fr & $1 \cdots$ & \\
\hline & ميانگين & \multicolumn{2}{|c|}{$r / \Lambda$} & \multicolumn{2}{|c|}{$r / V$} & \\
\hline & انحر اف معيار & \multicolumn{2}{|c|}{$\cdot 119$} & \multicolumn{2}{|c|}{.$/ 9 \pi$} & \\
\hline \multirow{5}{*}{ سطح تحصيلات } & بىسواد & rV & $s q$ & rs & sr & \multirow{4}{*}{$\mathrm{p}=\cdot / 9 r \mathrm{r}$} \\
\hline & ابتدايى & ir & rq & ir & rq & \\
\hline & راهنمايى & r & $\checkmark$ & f & 9 & \\
\hline & جمع & er & $1 \cdots$ & er & $1 \ldots$ & \\
\hline & متأهل & $\mu_{1}$ & $V^{c}$ & ro & ᄉr & \multirow{5}{*}{ 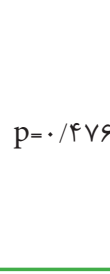 } \\
\hline \multirow{4}{*}{ وضعيت تأهل } & مجرد & 1 & r & r & $\Delta$ & \\
\hline & طلاق & 1 & r & 1 & r & \\
\hline & همسر فوتشده & 9 & rt & i & 1. & \\
\hline & 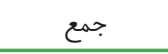 & pr & $1 \cdots$ & pr & $1 \cdots$ & \\
\hline \multirow{6}{*}{ مدت ابتلا } & r ( & 4 & 19 & $\wedge$ & 19 & \multirow{6}{*}{$\mathrm{p}=\cdot / \mathrm{Vr}$} \\
\hline & 9-9 سال & $\checkmark$ & IV & $\wedge$ & 19 & \\
\hline & +1 . & rq & 99 & rs & sr & \\
\hline & جمع & er & $1 \cdots$ & pr & $1 \ldots$ & \\
\hline & ميانغين & \multicolumn{2}{|c|}{$r / \Delta$} & \multicolumn{2}{|c|}{$\cdot / V^{\mu}$} & \\
\hline & انحراف معيار & \multicolumn{2}{|c|}{$r / \mathcal{F}$} & \multicolumn{2}{|c|}{$\cdot / \Lambda$. } & \\
\hline
\end{tabular}

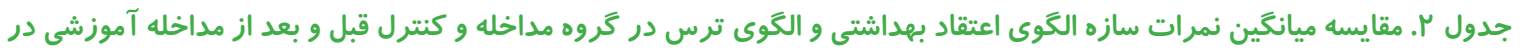

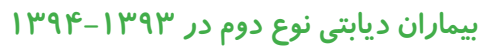

\begin{tabular}{|c|c|c|c|c|c|c|c|c|c|c|}
\hline \multirow{3}{*}{$\begin{array}{c}\text { آزمون تى زوجى } \\
\text { p-value }\end{array}$} & \multicolumn{4}{|c|}{ كروه كنترل (FY نفر) } & \multicolumn{5}{|c|}{ كروه مداخله (FY نفر) } & \multirow{3}{*}{ الكوى اعتقاد بهداشتى نماته } \\
\hline & \multicolumn{2}{|c|}{ بعد از مداخله } & \multicolumn{2}{|c|}{ ق قبل از مداخله } & \multirow{2}{*}{$\begin{array}{c}\text { آزمون تى } \\
\text { زوجى } \\
\text { p-value }\end{array}$} & \multicolumn{2}{|c|}{ بعد از مداخله } & \multicolumn{2}{|c|}{ قبل از مداخله } & \\
\hline & انحراف & ميانگين & انحراف & ميانغين & & انحراف & ميانكين & انحراف & ميانكين & \\
\hline$\cdot / 1 \cdot v$ & $\cdot / 10$ & $r / r$ & $\cdot / 19$ & $r / 9$ &.$/ \cdot 1$ & $p / \cdot 1$ & $p / r$ & . /Ar & $r / \Lambda$ & حساسيت درك شده \\
\hline.$/ \Delta \Delta$ & $\cdot / 9 \Delta V$ & $r / s$ & $\cdot / V \& 9$ & $r / \Delta$ &.$/ .1$ & $1 / 1 r$ & $f / 19$ & $\cdot / \mathrm{VV}$ & $r / r$ & شدت دركشده \\
\hline.$/ I V F$ & $19 / 09$ & $r s / s$ & $I V / Y F$ & $r \mu / r$ &.$/ \cdots 1$ & $\mid f / \Lambda$ & $\Delta 9 / r$ & $11 / 11$ & $r \Delta / r$ & ميزان ترس \\
\hline . /Var &.$/ 99$ & $r / s$ &.$/ 01 F$ & $F / 1$ & $\cdot / \cdot \cdot 1$ & $\cdot / r \Delta V$ & $\varphi / 19$ & $\cdot / r q$ & r & منافع درك شده \\
\hline.$/ 9 \Delta 4$ &.$/ 914$ & $r / \Delta$ & $\cdot / 414$ & $r / 9$ &.$/ \cdot 1$ & $\cdot / \Delta V^{\mu}$ & $r / \Delta$ & $1 / 9$ & $r / 9$ & موانع درك شده \\
\hline$\cdot / \Delta \mu$ & $\cdot / 094$ & $r / V$ & $\cdot / 9 Y \Lambda$ & $r / V$ & $\cdot / \cdot 1$ & $1 / I V$ & r/^ &.$/ 01 \mu$ & $r / s$ & خود كار آمدى \\
\hline
\end{tabular}




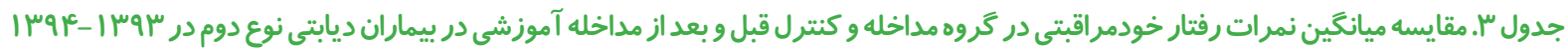

\begin{tabular}{|c|c|c|c|c|c|c|c|c|c|c|}
\hline \multirow{3}{*}{$\begin{array}{c}\text { آزمون تى زوجى } \\
\text { p-value }\end{array}$} & \multicolumn{4}{|c|}{ كروه كنترل (F F نفر) } & \multicolumn{5}{|c|}{ گروه مداخله (F F نفر) } & \multirow{3}{*}{ خويانكين نمرات } \\
\hline & \multicolumn{2}{|c|}{ بعد از مداخله } & \multicolumn{2}{|c|}{ ق قبل از مداخله } & \multirow{2}{*}{$\begin{array}{c}\text { آزمون تى } \text { زوجى } \\
\text { p-value }\end{array}$} & \multicolumn{2}{|c|}{ بعد از مداخله } & \multicolumn{2}{|c|}{ ق قبل از مداخله } & \\
\hline & انحراف & ميانغين & انحراف & ميانغين & & انحراف & ميانغين & انحراف & ميانكين & \\
\hline ומש/. & $\cdot / \wedge \Delta$ & r & $\cdot / V r$ & $r / 1$ &.$/ \cdots 1$ &.$/ 110$ & $f / s$ & $1 / 4$ & $r / q$ & رعايت رزيم غذايى \\
\hline.$/ 9 \Lambda$. & $1 / 9$ & 1 & $1 / 1$ & 1 &.$/ . .1$ &.$/ 9 \vee 4$ & $\Delta / r$ & $1 / r$ & $1 / \mu$ & مراقبت از پا \\
\hline .101 & $1 / 19$ & $1 / 1$. & $1 / 19$ & $\cdot / 1 \Lambda$ &.$/ \cdots 1$ & $\cdot / \wedge$ & $\Delta / r$ & $1 / .9$ &.$/ 9 \vee A$ & فعاليت بدنى \\
\hline$\cdot / r \cdot r$ &.$/ 94$. & 1 & ./Ars &.$/ 9 \vee 4$ & $\cdot / \cdot \cdot 1$ & $\cdot / \Delta \Delta$ & $r / 9$ &.$/ 910$ & $1 / r$ & كنترل قند خون \\
\hline$\cdot / V \Delta$ & $1 / f$ & $\Delta / \mu$ & $1 / \mu$ & $\Delta / r$ &.$/ \cdots 1$ & $1 / 10$ & 4 & $1 / V$ & $\Delta / \mathcal{F}$ & رعايت رزيم دارويى \\
\hline
\end{tabular}

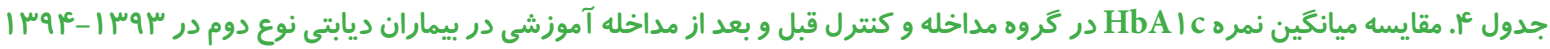

\begin{tabular}{|c|c|c|c|c|c|c|c|c|c|c|}
\hline \multirow{3}{*}{$\begin{array}{c}\text { آزمون تى زوجى } \\
\text { p-value }\end{array}$} & \multicolumn{4}{|c|}{ كروه كنترل (F F نفر) } & \multicolumn{5}{|c|}{ كروه مداخله (YF نفر) } & \multirow{3}{*}{ خودمر اقبتى نمرات } \\
\hline & \multicolumn{2}{|c|}{ بعد از مداخله } & \multicolumn{2}{|c|}{ ق ق قبل از مداخله } & \multirow{2}{*}{$\begin{array}{c}\text { آزمون تى زوجى } \\
\text { p-value }\end{array}$} & \multicolumn{2}{|c|}{ بعد از مداخله } & \multicolumn{2}{|c|}{ ق قبل از مداخله } & \\
\hline & انحراف & ميانغين & انحراف & ميانغين & & انحراف & ميانغين & انحراف & ميانگين & \\
\hline$\cdot /$ INV & $1 / 1 r$ & $N / \Delta 9$ & $1 / 48$ & $\Lambda / F \wedge$ &.$/ \ldots 1$ &.$/ G F$ & $V / \mu$. & $1 / 19$ & N/sq & $\mathrm{HbAlc}$ \\
\hline
\end{tabular}

كروه آزمون قبل از مداخله در مقايسه با سه ماه بعد از مداخله

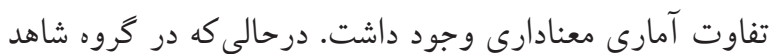
اين اختلاف معنادار نبود. مطالعه كذشته نشان داده است كه هيج تمايزى بين تهديد دركشده و ترس نيست و الكوى اعتقاد بهداشتى يك الكوى بيشكو يیى كننده رفتار است كه در مداخلات

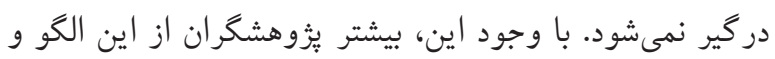

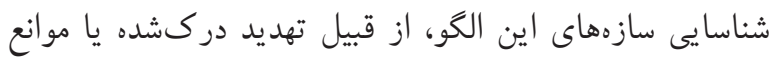
دركشده، تلاشى جهت كسترش يك مداخله براى تغيير رفتار

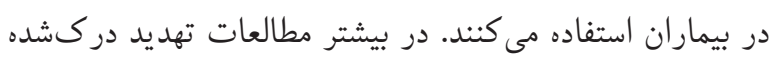
براى طراحى مداخلات استفاده مىشود؛ درحالى كه تشخيص بين

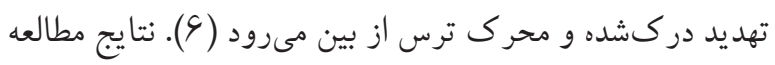

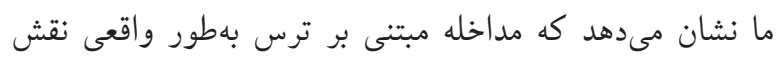

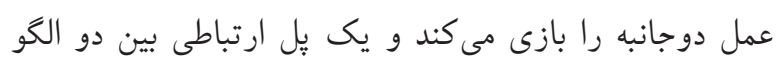

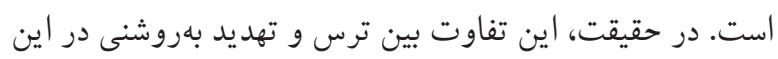
روش مشخص مىشود. يك سطح ترس ايجادشده مىتواند زمينه

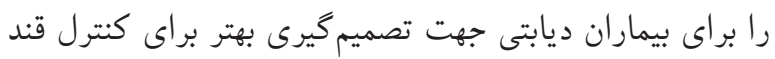
نتيجه تحقيق نشان داد بعد از انجام مداخله آموزشى تفاوت معنادارى در حساسيت دركشده، شدت دركشده، منافع دركشده و كاهش معنادارى در موانع دركشده بيماران گروه مداخله مشاهده

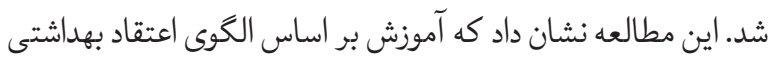

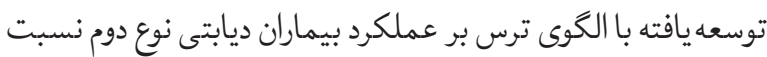

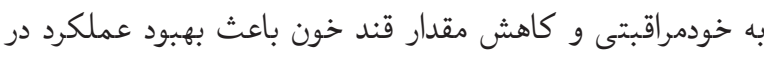
كروه آزمون در مقايسه با گروه كنترلشده است. نتايج تحقيق تجربى

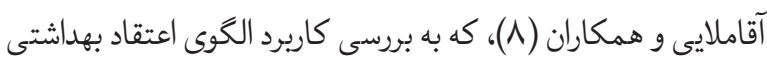
در تغيير رفتار بيماران ديابتى برداخته بودند، نشان داد بعد از انجام بـام بردان

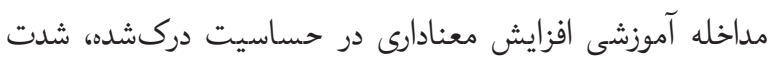
دركشده، منافع دركشده و كاهش معنادارى در موانع دركشده

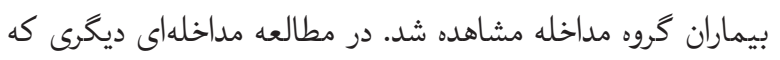

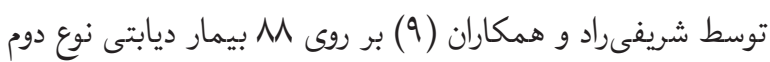

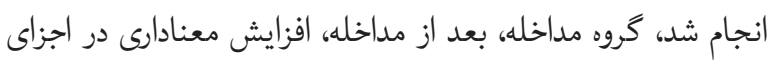
مختلف الخوى اعتقاد بهداشتى بهجز موانع دركشده داشتند. يافتهاى اين مطالعه نشان داد كه در ميانخين نمره ترس در خون خود ايجاد كند. 
مىرسد كه ارائه آموزشها در اين خصوص بتواند در بيشگيرى

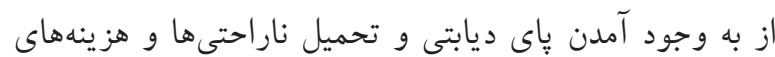
فراوان بر فرد و نظام بهداشتى سودمند باشد. يكى از مسائلى كه باعث نكرانى بيماران ديابتى مىشوده،

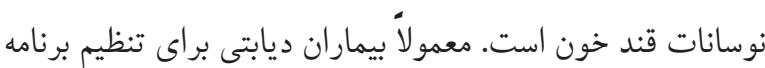

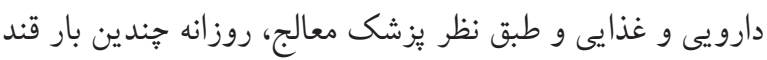
خونشان را در منزل كنترل مى كنند. نتايج مطالعه حاضر نشاندهنده افزايش معنادارى با توجه به كنترل قند خون در بين بيماران گروه

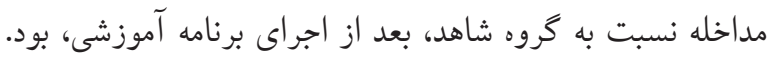

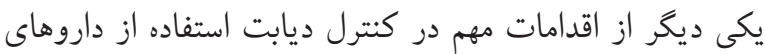
تجويزشده است. نتايج نشاندهنده افزايش معنادارى در استفاده از داروهاى تجويزشده در بين بيماران گروه مداخله نسبت به گروه

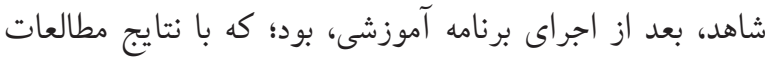
آقاملايى و همكاران (N) و روبين و همكاران(IV) همخخوانى دارد.

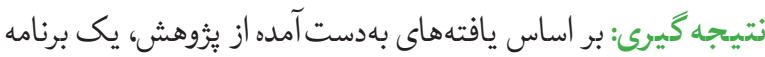

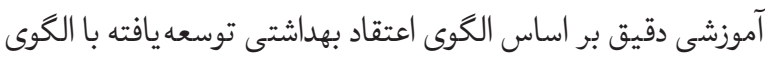

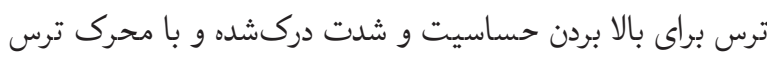

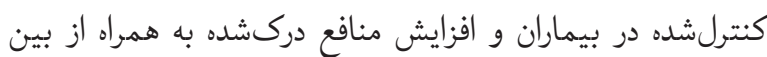

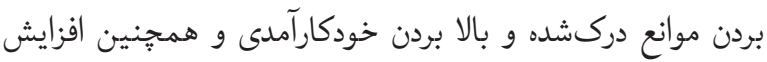
رفتارهاى خودمراقبتى و كاهش هموكلوبين A1C در بيماران ديابتى برد نوع دوم بسيار سودمند است. با توجه به اطلاعات بهدست آمده از

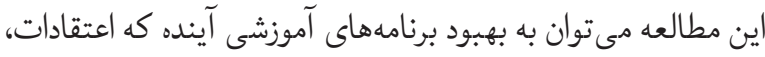

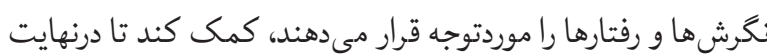
باعث ارتقاى بيشخيرى از عوارض ديابت نوع دوم، كاهش HbA1c و درنتيجه بهبود كيفيت زندكى افراد شود. اين يزووهش نيز همانند مطالعات ديكر داراى محدوديت هايى بود. ازجمله اين محدوديتها مىتوان به جمعيت موردبررسى اشاره كرد.

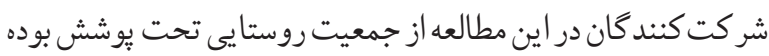
و تعميم نتايج بايد باحتياط صورت گيرد. با توجه به يافتههاى مطالعه

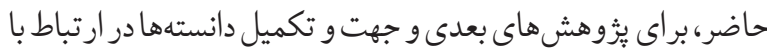

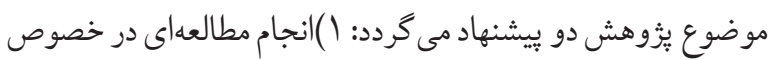

بعد از انجام مداخله آموزشى، ميانكين نمره HbA1c در

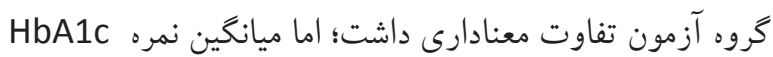
در گروه شاهد معنادار نشان داده نشد. اين نتيجه با يافتهاى مطالعات هايسلر و همكاران (1))، عسكرى و نقيبى (·))، جهانلو و همكاران (9) تطابق دارد؛ كه در مطالعات نامبرده نيز مداخله آموزشى شامل جنبههايى از درمان ديابت كه بيشتر بان مهارتهاى خود بيمار مرتبط بوده و بيمار را درگير مىكند در كاهش HbA1c مؤثرتر بوده است. ضرورت رعايت رزيم غذايى بهعنوان يك عامل باهميت در كنترل بيمارى شناخت شده است و درمان تغذيهاى يك جزء ضرورى در برنامه درمان مبتلايان به ديابت است. استفاده از روشهاى تغذيهاى، راهكارى بهصرفه ازنظر اقتصادى در كاهش عوارض، مشكلات و مرگومير ناشى

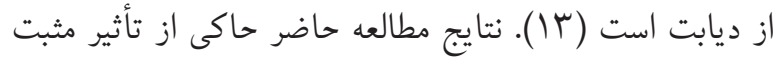
مداخله مبتنى بر الخوى اعتقاد بهداشتى توسعهيافته بر رعايت

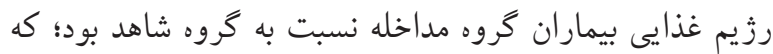

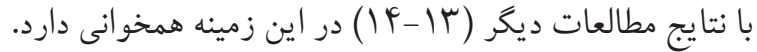
مطالعات متعدد نشان مىدهند بيشتر از •^ ٪ از افراد ديابتى فعاليت بدنى كافى ندارند و كاهش فعاليت بدنى باعث افزايش

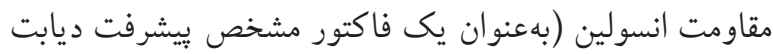
نوع دوم مىشود (10). نتايج مطالعه حاضر نشاندهنده افزايش معنادار فعاليت بدنى در بين بيماران گرووه مداخله است. در اين

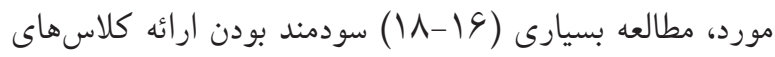

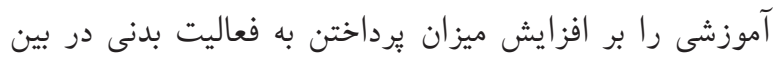
بيماران ديابتى نشان دادهاند. يكى ديكر از جنبههاى خودمر اقبتى مورد بررسى در اين مطالعه

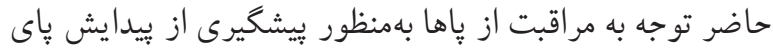

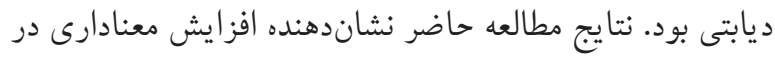

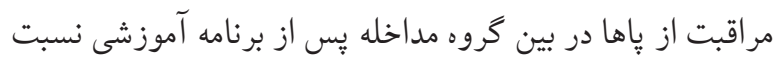
به گروه شاهد بود؛ كه با نتايج مطالعات ديكر (19-1 (†) در اين

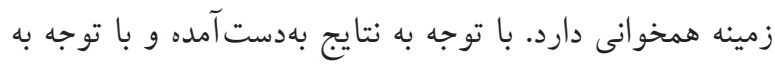

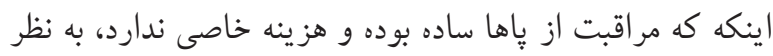


است. لذا يثوهشگران بر خود لازم مىدانند تا از كليه مسئولين محترم دانشگاه علوم يزشكى گيلان كه حمايت مادى و معنوى لازم براى اجراى اين مطالعه را فراهم كردند، نهايت تشكر را داشته باشند. همجنين بر خود لازم ميدانيم از كاركنان محترم بخش واحد ييشخيرى و مبارزه با بيمارىهاى مركز بهداشت شهرستان رشت و كاركنان محترم مراكز سلامت جامعه كوجصفهان و خمام شهرستان رشت و همجنين افراد شركت كننده در اين مطالعه، كه ما را در انجام اين تحقيق يارى كردند، سياسگزارى كنيم.

\section{References:}

1. World Health Organization. Global report on diabetes. (http://wwwwhoint) 2016.

2. Hu FB. Globalization of Diabetes The role of diet, lifestyle, and genes. Diabetes care. 2011;34(6):1249-57.

3. Haery SM, Tehrani H, Olyaeimanesh A, Nedjat S. Factors Influencing the Social Health of Employees of the Ministry of Health and Medical Education in Iran. Iranian Journal of Health Education and Health Promotion. 2016;3(4):311-8.

4. Nijland N, Seydel ER, van Gemert-Pijnen JE, Brandenburg B, Kelder SM, Will M, editors. Evaluation of an Internet-based application for supporting self-care of patients with diabetes mellitus type 2. eHealth, Telemedicine, and Social Medicine, 2009 eTELEMED'09 International Conference on; 2009: IEEE.

5. Vahedian-Shahroodi M, Elaheh L-m, Esmaily $H$, Tehrani $H$, Hamidreza $\mathrm{M}-\mathrm{H}$. Prediction of osteoporosis preventive behaviors using the Health Belief Model. Iranian Journal of Health Education and Health Promotion. 2014;2(3):199-207.

6. Jahanlou AS, Lotfizade M, Karami NA. A New Behavioral Model (Health Belief Model Combined with Two Fear Models): Design, Evaluation and Path Analysis of the Role of Variables in Maintaining Behavior: INTECH Open Access Publisher; 2013.

7. Shamsi M, Sharifirad G, Kachoyee A, Hassanzadeh A. The effect of educational program walking based on health belief model on control sugar in woman by type 2 diabetics. Iranian Journal of Endocrinology and Metabolism. 2009;11(5):490-9, 597.

8. Aghamolai T, EfteKhar H, Mohamad K, editors. Application of health belief model in diabetic patients. Congress of health promotion Payesh; 2006.

9. Sharifirad Gh, Entezari M, Kamran A, Azadbakht L. Efficacy of nutrition education to diabetic patient: Application of health belief model. Iranian Journal of Diabetes and Lipid Disorders. 2008;7(4):379-86.

10. Asghari M, Naghibi S, F R. An Investigation of the Effect of Training on Self-Care Promotion in Type 2 Diabetic
تأثير روش مداخله بر اساس الكوى اعتقاد بهداشتى توسعهيافته با الكوى ترس براى ارتقاى رفتار خودمراقبتى در بيماران ديابتى نوع دوم در ساير استانها با ويزگى فرهنكى، اجتماعى متفاوت؛ و ب) بررسى و مقايسه دو روش مداخله الخوى اعتقاد بهداشتى و الخوى اعتقاد بهداشتى توسعه يافته براى ارتقاء و پِايدارى رفتار خودمراقبتى در بيمار ان ديابتى.

Patients in Noor Health Center in 2015. Journal of health research in communiy. 2015;1(2):22-8.

11. Heisler M, Smith DM, Hayward RA, Krein SL, Kerr EA. How well do patients' assessments of their diabetes selfmanagement correlate with actual glycemic control and receipt of recommended diabetes services? Diabetes care. 2003;26(3):738-43.

12. Smith KM, Boling E. What Do We Make of Design? Design as a Concept in Educational Technology. Educational Technology. 2009;49(4):3-17.

13. Sharifirad G, Entezari M, Kamran A, Azadbakht L. The effectiveness of nutritional education on the knowledge of diabetic patients using the health belief model. Journal of Research in Medical Sciences. 2009;14(1):1-6.

14. Whittemore R. Strategies to facilitate lifestyle change associated with diabetes mellitus. Journal of Nursing Scholarship. 2000;32(3):225-32.

15. Afkhami Ardakani M RM. Type 2 diabetes and its risk factorsJ of Rafsanjan University of Medical Sciences2006;4(4):65-348.

16. Kirk A, Mutrie N, Maclntyre P, Fisher M. Increasing physical activity in people with type 2 diabetes. Diabetes Care. 2003;26(4):1186-92.

17. Rubin RR, Peyrot M, Saudek CD. Differential effect of diabetes education on self-regulation and life-style behaviors. Diabetes Care. 1991;14(4):335-7.

18. Walker K, O'Dea K, Gomez M, Girgis S, Colagiuri R. Diet and exercise in the prevention of diabetes. Journal of human nutrition and dietetics. 2010;23(4):344-52.

19. Hazavehei S, Sharifirad G, Mohabi S. The effect of educational program based on health belief model on diabetic foot care. International Journal of Diabetes in Developing Countries. 2007;27(1).

20. Patout CA, Birke JA, Horswell R, Williams D, Cerise FP. Effectiveness of a comprehensive diabetes lower-extremity amputation prevention program in a predominantly lowincome African-American population. Diabetes Care. 2000;23(9):1339-42. 